\title{
Fenologia de quatro espécies tóxicas de Senecio (Asteraceae) na região Sul do Rio Grande do Sul ${ }^{1}$
}

\author{
Fernando Sérgio Castilhos Karam² ${ }^{2}$ Maria del Carmen Méndez ${ }^{3}$, \\ João André Jarenkow ${ }^{4}$ e Franklin Riet-Correa ${ }^{5}$
}

\begin{abstract}
Karam F.S.C., Méndez M.C., Jarenkow J.A. \& Riet-Correa F. 2002. [Phenology of four poisonous Senecio (Asteraceae) species in southern Rio Grande do Sul, Brazil.] Fenologia de quatro espécies tóxicas de Senecio (Asteraceae) na região Sul do Rio Grande do Sul. Pesquisa Veterinária Brasileira 22(1):33-39. Laboratório de Toxicologia, Fac. Med. Vet., URCAMP, Bagé, RS 96400-110, Brazil. E-mail: fernando@alternet.com.br

This study aimed to determine the phenology of Senecio brasiliensis, S. oxyphyllus, S. heterotrichius and S. selloi, and their relationship with cattle poisoning in the southern region of the State of Rio Grande do Sul, Brazil. The phenology was studied during two years in the rural area of the municipalities of Bagé and Capão do Leão. These phenological observations were made at monthly intervals during the vegetative phase, and every 15 days during the reproductive period. The plants were observed from emergence until the dispersal of seeds, considering their vigor and their relationship with environmental factors. The results indicate that whenever the environmental conditions, like moisture and light, were favorable, Senecio spp emerge. The vegetative phenophases are practically constant during all life cycle of the plant and the whole year. Unfavorable environmental factors like water stress, soil management and damage by insects, associated or not, can alter the cycle of the plants and determine their permanence in the environment. The majority of the species studied behaved like annual and monocarpic plants. According with the permanence during the two years of observation, the most persistent species in the environment was $S$. heterotrichius $(15 \%$ of the plants persisted during the two year period), followed by $S$. selloi $(2,8 \%)$ and $S$. brasiliensis $(0,9 \%)$. S. oxyphyllus did not persist for more than one year.
\end{abstract}

INDEX TERMS: Phenology, poisonous plants, Senecio brasiliensis, Senecio oxyphyllus, Senecio heterotrichius, Senecio selloi, Asteraceae.

RESUMO.- O objetivo principal desse trabalho foi determinar a fenologia de Senecio brasiliensis, S. oxyphyllus, $S$. heterotrichius e $S$. selloi, e relacioná-la com a epidemiologia da

\footnotetext{
${ }^{1}$ Aceito para publicação em 8 de fevereiro de 2002.

Parte da dissertação de mestrado do primeiro autor, Pós-Graduação em Veterinária, Patologia Veterinária, Universidade Federal de Pelotas (UFPel). Projeto com apoio do PRONEX e da FAPERGS.

${ }^{2}$ Laboratório de Toxicologia, Faculdade de Medicina Veterinária, Centro de Ciências Rurais, Universidade da Região da Campanha, Av. Tupy Silveira 2099, Bagé, RS 96400-110. E-mail: fernando@alternet.com.br

${ }^{3}$ Laboratório Regional de Diagnóstico, UFPel, 96010-900 Pelotas, RS. E-mail: nane@ufpel.tche.br

${ }^{4}$ Departamento de Botânica, Instituto de Biociências, Universidade Federal do Rio Grande do Sul, Av. Bento Gonçalves 9500, Bloco 4, Prédio 43433, Porto Alegre, RS 91501-970. E-mail: jarenkow@portoweb.com.br

${ }^{5}$ Laboratório Regional de Diagnóstico, UFPel, 96010-900 Pelotas, RS. E-mail: riet@ufpel.tche.br
}

intoxicação em bovinos, na região sul do Rio Grande do Sul. $\mathrm{O}$ estudo fenológico foi feito durante dois anos nos municípios de Bagé e Capão do Leão. As leituras foram mensais durante o período vegetativo e quinzenais no período reprodutivo das espécies, para observação desde sua emergência até dispersão de sementes, avaliando-se o vigor, e relacionando essas variáveis com fatores ambientais. Os resultados permitiram concluir que durante todo o ano há emergência de plantas de Senecio spp, desde que haja condições ambientais favoráveis, como umidade e luz, e as fenofases vegetativas são praticamente constantes durante todo o ciclo da planta. Fatores ambientais desfavoráveis como o déficit hídrico, o manejo do solo e o dano de insetos, associados ou não, podem alterar o ciclo das plantas e serem determinantes para a sua permanência no ambiente. A maioria dos exemplares, das quatro espécies, comportou-se como anual e monocárpica. A espécie mais persistente no ambiente foi $S$. heterotrichius $(15 \%$ das plantas persistiram durante os dois anos de estudo), se- 
guida de $S$. selloi $(2,8 \%)$ e $S$. brasiliensis $(0,9 \%)$. S. oxyphyllus não permaneceu no ambiente por mais de um ano.

TERMOS DE INDEXAÇÃO: Fenologia, plantas tóxicas, Senecio brasiliensis, Senecio oxyphyllus, Senecio heterotrichius, Senecio selloi, Asteraceae.

\section{INTRODUÇÃO}

O estudo fenológico aborda as manifestações fisionômicas das diferentes fases das plantas, incluindo desde a sua emergência até seu declínio, revelando o seu comportamento fitossociológico (Fournier 1976, Cestaro 1984, Costa et al. 1988, Beskow 1995, Madanes et al. 1996, Morellato \& Leitão-Filho 1996, Machado et al. 1997, Larcher 2000). Observações fenológicas são realizadas especialmente em espécies de importância econômica para a compreensão dos mecanismos que regem suas diferentes fenofases. Portanto, o conhecimento da fenologia de plantas indesejáveis é fundamental para que se desenvolva um controle biológico, assim como essas informações são necessárias para se determinar práticas corretas de manejo que previnam intoxicações (Vitorino 1997, Riet-Correa \& Medeiros 2000). O presente estudo acompanhou o desenvolvimento de Senecio brasiliensis, S. oxyphyllus, S. heterotrichius e S. selloi (Asteraceae) que, na região sul do Rio Grande do Sul, são plantas freqüentemente associadas a intoxicações nos animais, principalmente em bovinos (Méndez et al. 1990, Driemeier et al. 1991, Driemeier \& Barros 1992, Kissmann \& Groth 1992, Barros et al. 1992, Liddell et al. 1992, Méndez 1993, Méndez \& Riet-Correa 2000).

A intoxicação por espécies de Senecio (seneciose) em bovinos provoca perdas econômicas importantes pela queda na produtividade dos animais, e mesmo por sua morte, pois os alcalóides pirrolizidínicos, princípios ativos tóxicos da planta, determinam uma lesão irreversível e progressiva no fígado daqueles que a consumirem (Bull 1955, Méndez 1993, Pearson 1993, Méndez \& Riet-Correa 2000). Estima-se que no Rio Grande do Sul, Estado que conta com uma população bovina de 13 milhões de cabeças, $5 \%$ dessa população morre anualmente, equivalendo a 650.000 animais por ano. Desses, $10 \%$ a $14 \%$ morrem devido a intoxicações por plantas, o que corresponde de $64 \mathrm{mil}$ a 90 mil cabeças/ano. Estimando um preço médio de US\$ 200 por animal, apenas as perdas diretas por mortes atribuídas a plantas tóxicas, no Rio Grande do Sul, ficam entre US\$ 12 a 18 milhões anualmente. Considerando que $50 \%$ das mortes causadas por plantas tóxicas devem-se à intoxicação por diversas espécies de Senecio, conclui-se que esta intoxicação ocasiona perdas econômicas de, em média, US\$ 7,5 milhões anuais (Méndez 1997, Riet-Correa $\&$ Medeiros 2000).

Como objetivo geral este trabalho buscou determinar as fases fenológicas das espécies acompanhadas e aportar dados para o estudo epidemiológico da seneciose.

\section{MATERIAL E MÉTODOS}

O estudo fenológico acompanhou plantas de Senecio brasiliensis (Spreng.) Less, S. oxyphyllus DC., S. heterotrichius DC. e S. selloi (Spreng.)
DC., em três áreas de estudo, nos municípios de Bagé (RS) e Capão do Leão (RS).

Área 1: localizada no Centro de Ciências Rurais da Universidade da Região da Campanha (CCR-URCAMP), Bagé (RS), a 31 ${ }^{\circ} 20^{\prime} 13$ "S e $54^{\circ} 06^{\prime} 21^{\prime \prime} \mathrm{W}$, altitude aproximada de $216 \mathrm{~m}$, onde foi acompanhado o desenvolvimento de S.brasiliensis e S. oxyphyllus.

Caracterização do solo: trata-se de um LuvisSOlo HiPOCRôMICo Órtico típico (Embrapa 1999), unidade de mapeamento "Bexigoso" (Brasil 1973, Macedo 1984).

Essa área compreendia dois locais próximos, num terreno alterado por roçadas e/ou anteriormente trabalhado para lavouras, com grande número de plantas ruderais. Um deles era um local permanentemente exposto ao sol, mais alto em relação ao outro que, por sua vez, era situado à margem de uma pequena mata ciliar e, no inverno, recebia sol das oito horas até em torno das 16 horas, num local freqüentemente úmido. A área caracteriza-se como campo úmido de várzea.

Área 2: localizada na Fazenda São Manoel, distrito de Aceguá, Bagé (RS), a $31^{\circ} 23^{\prime} 24,4^{\prime \prime} S$ e $54^{\circ} 07^{\prime} 50,7^{\prime \prime} \mathrm{W}$, altitude aproximada de $151 \mathrm{~m}$, onde foi acompanhado o desenvolvimento de $S$. brasiliensis e S. oxyphyllus.

Caracterização do solo: trata-se de um VerTISSOLo EBÂNiCo Órtico chernossólico (Embrapa 1999), unidade de mapeamento "Aceguá" (Brasil 1973, Macedo 1984).

Essa área situava-se no topo de uma coxilha, em campo nativo, anteriormente sujeito ao pastoreio de bovinos e eqüinos e era, eventualmente, roçado. No segundo ano, esse local foi acrescido de uma área contígua, na qual tinha permanecido o pastoreio. Em qualquer época do ano, o sol incidia desde o amanhecer e diminuía sua incidência direta a partir das 13 horas devido à presença de árvores próximas. A área caracteriza-se como campo seco de coxilha.

Área 3: localizada nas bordas leste e oeste do Horto Botânico "Ir. Teodoro Luís", da Universidade Federal de Pelotas - UFPel, Capão do Leão (RS), a $31^{\circ} 52^{\prime} 00^{\prime \prime} \mathrm{S}$ e $52^{\circ} 21^{\prime} 24^{\prime \prime} \mathrm{W}$, altitude aproximada de $13 \mathrm{~m}$.

Caracterização do solo: a borda leste caracteriza-se por um NeOSSOlo QUARTZARÊNICO Órtico típico (Embrapa 1999), sem unidade de mapeamento; a borda oeste constitui-se por ARGISSOLO VERMELHO AmARelo Distrófico típico (Embrapa 1999), com unidade de mapeamento "Camaquã" (Brasil 1973).

Essa área localizava-se nas bordas de uma mata nativa, com algumas alterações no terreno e em sua flora devido a antigas atividades humanas e/ou pela presença de animais exóticos. Atualmente é uma área preservada. Na borda leste, local arenoso e com longa exposição solar, encontrava-se a população de $S$. heterotrichius. Na borda oeste, ao longo da margem da mata e também no seu interior, estavam situadas as populações de $S$. brasiliensis e $S$. selloi. Nesse lado, a exposição solar era menor e, o solo, mais úmido em relação ao da borda leste.

Caracterização do clima nas Áreas 1, 2 e 3: nas regiões de estudo, segundo sistema de Köppen, o clima caracteriza-se por macrotérmico temperado úmido (Cfa), onde a temperatura do mês mais frio está entre $3^{\circ}$ e $18^{\circ} \mathrm{C}$ e a temperatura do mês mais quente é superior a $22^{\circ} \mathrm{C}$ (Moreno 1961); ou clima mesotérmico brando superúmido sem estação seca, tipo temperado (Nimer 1990).

As áreas de observação fenológica estavam protegidas do pastoreio. Nessas áreas, o número de plantas (ou indivíduos) por espécie foi estabelecido desde que houvesse uma representação 
significativa para uma população, que seria de, no mínimo, dez exemplares. Cada indivíduo foi inicialmente marcado com uma estaca e identificado com um número. $\mathrm{O}$ acompanhamento foi realizado durante dois anos com leituras mensais (a cada 30 dias) na fase vegetativa (janeiro a agosto) e, quinzenal, no período reprodutivo (setembro a dezembro).

O período completo do estudo fenológico compreendeu abril de 1998 a agosto de 2000. Para a leitura das fenofases dos indivíduos foram considerados como parâmetros a ocorrência de brotos vegetativos (BV), folhas jovens (FJ), folhas adultas (FA), flores (FI), frutos maduros (FrM), e classificados quanto à intensidade do seu vigor em forte $(+)$, média $( \pm)$, fraca $(-)$ e nula ou zero $(0)$.

o comportamento fenológico das espécies estudadas foi representado por fenogramas referentes à freqüência de ocorrência das fenofases. Estes dados foram calculados por espécie, por população, por área e por mês, durante o ano fenológico, adaptados de Castellani et al. (1999):

$$
\begin{gathered}
\text { Frequiência de ocorrência da } \mathrm{sp}_{\mathrm{x}}=\frac{\text { Número de indivíduos na fenofase }}{\mathrm{a}} \\
\text { na fenofase }
\end{gathered}
$$

$\mathrm{O}$ vigor de cada planta foi avaliado considerando-se $\mathrm{o}$ aspecto da mesma, em adaptação feita à escala de Braun-Blanquet (MuellerDombois \& Ellenberg 1974).

\section{RESULTADOS}

Os resultados apresentados são gerais, representando a população de todas as espécies acompanhadas, por área de estudo.

Na Fig. 1 estão representados o comportamento fenológico de Senecio brasiliensis e S. oxyphyllus, nas Áreas 1 e 2, e as médias de temperatura e a precipitação dessa região. Notase que as fases vegetativas são constantes e sua maior expressão se dá quando há maior precipitação. As fases reprodutivas ocorrem em períodos de menor precipitação e de elevação da temperatura. As falhas de registro fenológico, de abril a junho de 1999, correspondem a um período de baixas precipitações, quando não houve emergência de mudas, ou estas permaneceram estacionadas no seu desenvolvimento.

A Fig. 2 apresenta o desenvolvimento fenológico de $S$. brasiliensis, S. heterotrichius e S. selloi, na Área 3, e as médias de temperatura e a precipitação para essa região. Nota-se a constância das fases vegetativas, com maior incidência num período de maior precipitação, enquanto floração e frutificação restringem-se a períodos menos chuvosos e de temperaturas mais elevadas.
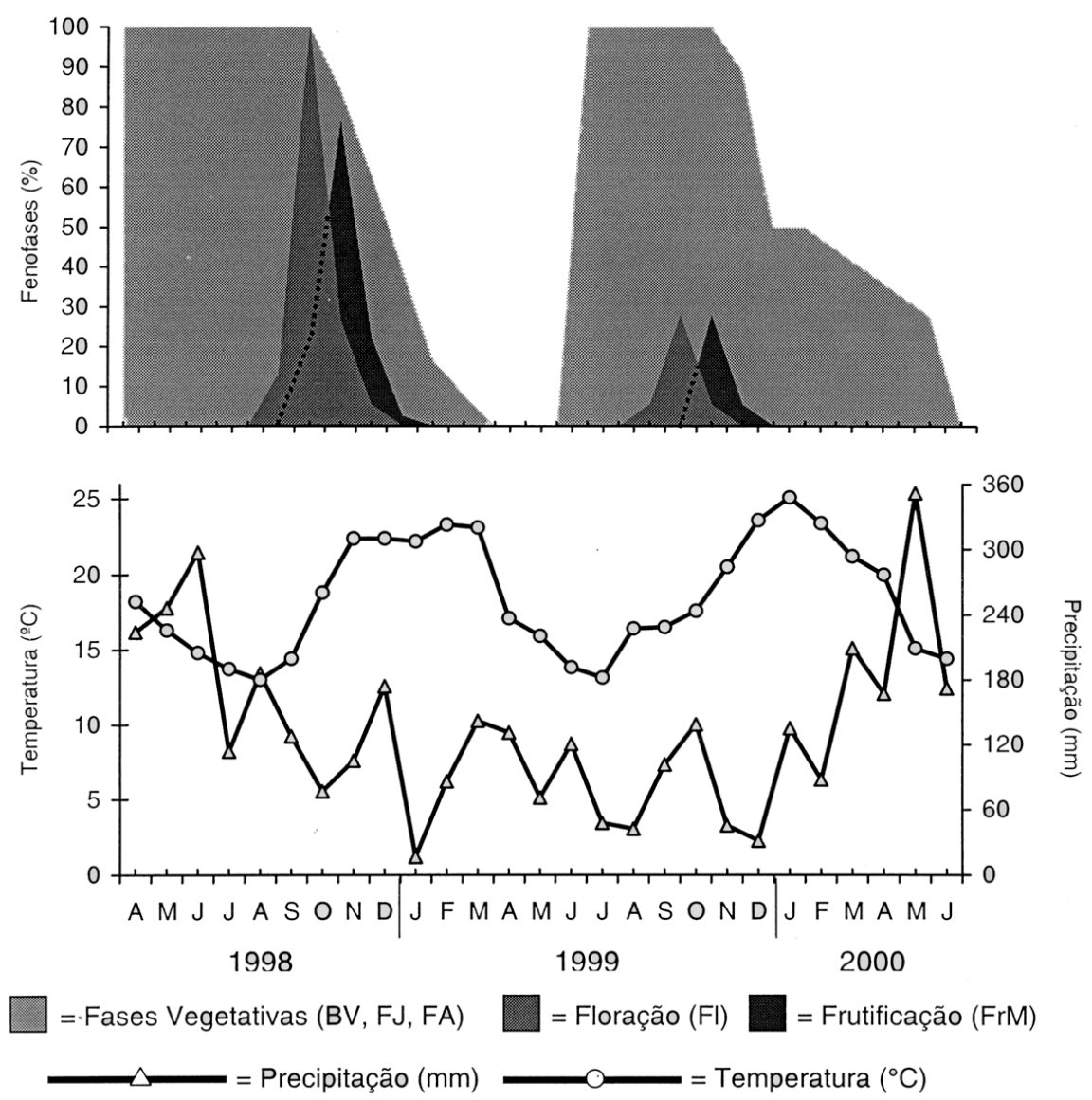

Fig. 1. Comportamento fenológico de Senecio brasiliensis e S. oxyphyllus nas Áreas 1 e 2 (Bagé-RS), de abril de 1998 a março de 1999 e de julho de 1999 a junho de 2000, com temperaturas médias e precipitações correspondentes ao mesmo período para a região. 

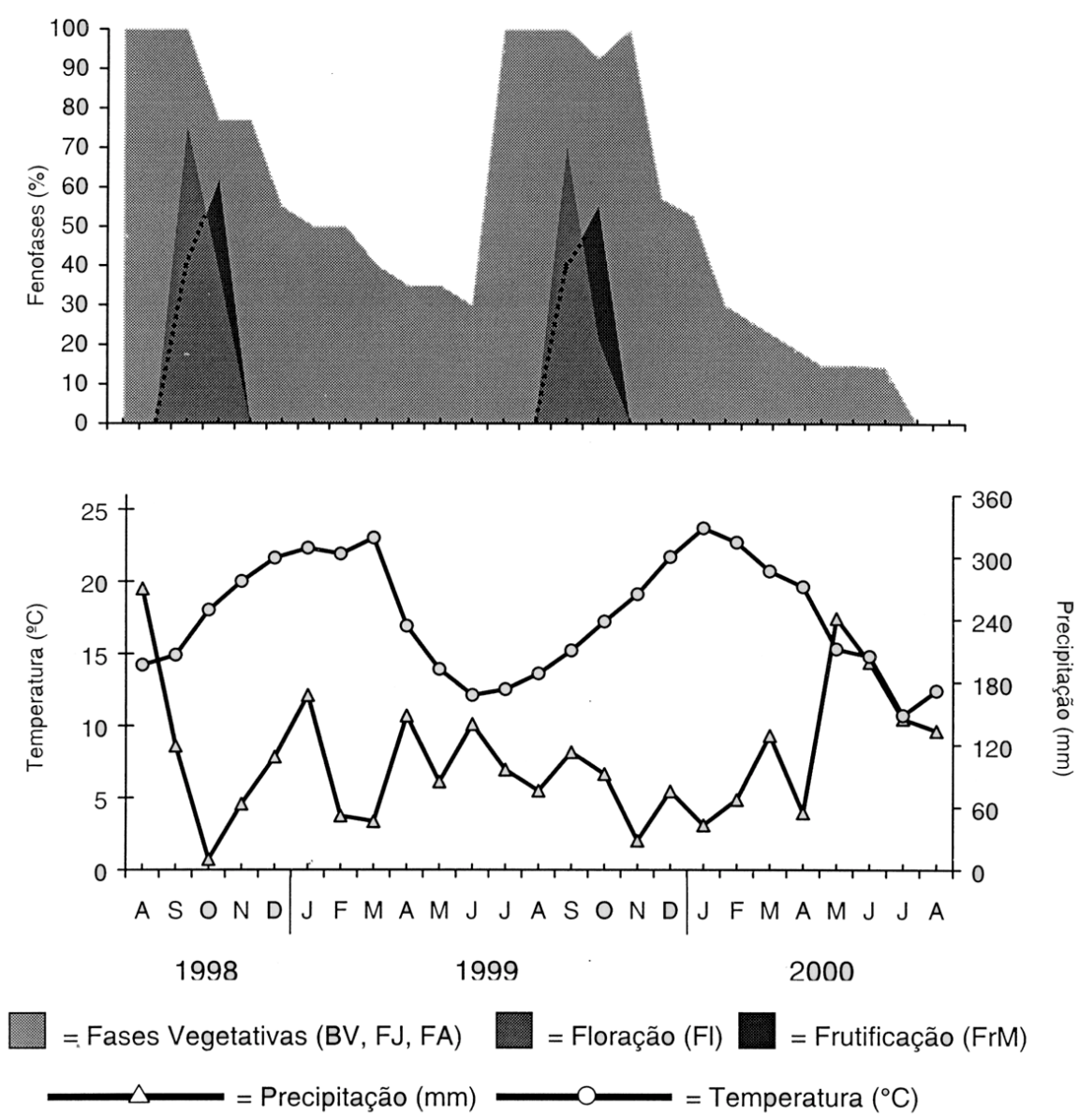

Fig. 2. Comportamento fenológico de Senecio brasiliensis, S. heterotrichius e S. selloi na Área 3 (Capão do Leão-RS), de agosto de 1998 a agosto de 2000, com temperaturas médias e precipitações correspondentes ao mesmo período para a região.

Nas diferentes áreas da fenologia, observou-se que permaneceram, durante os dois anos de estudo, um indivíduo de $S$. brasiliensis, correspondendo a $0,9 \%$ daqueles que tiveram o desenvolvimento acompanhado, um indivíduo de S. selloi $(2,8 \%)$ e seis de $S$. heterotrichius (15\%). Embora alguns indivíduos de $S$. oxyphyllus tenham permanecido viáveis ao final do primeiro ano, morreram no início do segundo ano de observação, não permanecendo no ambiente.

A presença de insetos permanentes ou transitórios foi uma observação constante. Insetos broqueadores de caule e de botões florais, mas especialmente desfolhadores como Phaedon confinis (Caxambú 1999), lagartas de Pericopis sacrifíca (Eduardo Silva 2000, UFPel, comunicação pessoal) e Phaedon sp. e o besouro Systena s-littera tenuis (Luciano Moura 2000, Fundação Zoobotânica do Rio Grande do Sul, comunicação pessoal), foram encontrados isolados ou associados, principalmente em S. brasiliensis e S. selloi.

\section{DISCUSSÃO E CONCLUSÕES}

Para o controle das intoxicações por plantas é importante conhecer os fatores que determinam a ocorrência e frequiência das mesmas no meio ambiente. Alguns fatores que influ- em sobre a população das diversas espécies de Senecio são parcialmente conhecidos. Sabe-se que os ovinos podem ser utilizados para o controle de espécies de Senecio porque, na maioria das vezes, consomem a planta sem serem afetados (Méndez \& Riet-Correa 2000, Tokarnia et al. 2000). Por outro lado, alguns fatores como a aração do solo ou outras práticas que deixam o mesmo descoberto favorecem a germinação de sementes de plantas indesejáveis como Senecio spp. (Thompson et al. 1977, Coombs et al. 1991, Beskow 1995). Não se pode pensar em controlar espécies de Senecio ou outras plantas por controle biológico ou medidas agronômicas (roçadas, aração, utilização de herbicidas, adubação) sem se conhecer alguns aspectos importantes do seu ciclo biológico (emergência, brotação e dispersão de sementes, permanência da planta no ambiente e estabelecimento em diferentes ambientes). Esta informação somente pode ser obtida mediante estudos de fenologia, que nos permitam conhecer o ciclo biológico da planta.

A abordagem correlativa entre o clima e a fenologia combina questões de botânica aplicada com questões meteorológicas (Larcher 2000). Logo, a fenologia está diretamente ligada aos fatores ambientais, pois eles regulam os 
fenômenos biológicos (Borgignon \& Piccolo 1981). Ao estudar-se $S$. brasiliensis e S. oxyphyllus nas áreas da região de Bagé, no segundo ano fenológico, observou-se que praticamente toda a população morreu no verão seguinte a sua emergência, durante ou logo após um período de baixa precipitação (Fig. 1). As plantas nascidas no inverno não conseguem desenvolver um sistema radicular com profundidade suficiente para suportar um eventual período seco no verão seguinte, concordando com o observado para Senecio jacobaea na Nova Zelândia (Beskow 1995). Como as áreas do estudo fenológico permaneceram fechadas, protegidas do pastoreio, a vegetação de cobertura cresceu muito, diminuindo a incidência de luz e a temperatura, e não foi observada a emergência de mudas no segundo ano de estudo, especialmente na Área 2. Da mesma forma, na Área 1, as plantas mais expostas ao sol eram mais vigorosas, denotando-se que são plantas heliófilas e não aptas a sobreviver numa comunidade fechada (Harper 1958, Cabrera \& Klein 1975). A incidência de luz e a temperatura são fatores considerados importantes para a germinação de sementes e o estabelecimento de plântulas (Thompson et al. 1977, Beskow 1995).

Avaliando-se a fenodinâmica dessa população, entre o primeiro e o segundo ano, observa-se que as fenofases vegetativas, especialmente $\mathrm{BV}$ e FJ, foram mais freqüentes sempre que ocorriam precipitações e, no ano de 1998, por ter-se caracterizado como úmido a superúmido (Walter 1977), essas fases mostraram-se mais vigorosas, evidenciando a importância da precipitação para o estágio vegetativo de diversos vegetais (Miranda 1995). As fases reprodutivas, ao contrário das vegetativas, parecem ser sempre estimuladas pela maior exposição solar e pelo aumento na temperatura, sem excesso de umidade no solo (Castellani et al. 1999). No período reprodutivo as leituras fenológicas foram quinzenais porque, nessa fase, os eventos ocorrem de forma mais rápida e intensa.

Em todas as áreas de observação, a população acompanhada manifestou as fases vegetativas durante todo o período, sendo mais expressivas quando havia maior luminosidade e precipitação e, as fases reprodutivas, quando foi maior a temperatura e o fotoperíodo (Fig. 1 e 2).

Na Área 3, observou-se a existência de S. heterotrichius em local sempre mais exposto ao sol e principalmente em área de solo mais arenoso, parecendo tratar-se de espécie psamófila e, portanto, localizada no seu local de preferência. Essa população apresentou todas as fenofases durante o período acompanhado, apresentando uma maior uniformidade de ocorrências. S. selloi apresentou similaridade de manifestações vegetativas, mas, quanto à floração, essa fenofase ocorreu apenas nas plantas mais expostas ao sol, que, também, se mostraram mais vigorosas, similar ao comportamento de S. brasiliensis nessa área. Isso reforça a importância da luz para o vigor e reprodução de diferentes espécies vegetais, assim como para o comportamento de espécies invasoras em áreas sombreadas dentro de matas (Borgignon \& Piccolo 1981, Cestaro 1984). Supõe-se, portanto, que todas as espécies desse estudo sejam preferencialmente fotoblásticas positivas, como S. jacobaea (Beskow 1995).
Nas quatro espécies, a dispersão de sementes ocorreu após a formação de frutos maduros, fenofases que ocorrem quando as fases vegetativas são menos expressivas. Nas espécies de Senecio, por serem principalmente anemocóricas, ou seja, que se dispersam pelo vento, o fato de os órgãos vegetativos estarem em senescência favorece a dispersão dos aquênios pelo vento (Miranda 1995, Morellato \& Leitão-Filho 1996), mas os diásporos encontram na mata uma barreira natural, limitando seu habitat até à beira das mesmas (Cabrera \& Klein 1975, Matzenbacher 1998). No entanto, parece haver uma superestimativa em relação à importância do vento como agente dispersor de diversas Asteraceae, pois nem todo pápus que se vê ao vento carrega consigo uma semente (Wagner Beskow 1998, Massey University, comunicação pessoal).

Quanto ao ciclo de vida reprodutivo, a maioria dos exemplares das espécies de Senecio acompanhadas comportou-se como anual e monocárpica, i. e., que florescem uma vez e morrem. No entanto, a reprodução dessas espécies pode ser perturbada em função de variações na temperatura ambiental, períodos de déficit hídrico, por ação de insetos predadores ou por práticas como roçadas, alterando seu ciclo reprodutivo, em função dos danos sofridos (Harper \& Wood 1957, Harper 1958 , van der Meijden \& van der Waals-Kooi 1979, Costa et al. 1988, Beskow 1995).

Os insetos são agentes importantes a considerar para o controle biológico de espécies de Senecio. Trabalhos realizados no estado de Oregon, Estados Unidos, demonstraram a eficiência de três insetos (Tyria jacobaeae, Longitarsus jacobaeae e Pegohylemyia seneciella) no controle biológico de Senecio jacobaea (Coombs et al. 1991, McEvoy et al. 1991, Coombs et al. 1996, Coombs et al. 1997). A presença de insetos causando danos importantes nas espécies de Senecio estudadas, principalmente $S$. brasiliensis e $S$. selloi, justamente as espécies envolvidas com maior freqüência na epidemiologia da seneciose na região sul do Rio Grande do Sul (Karam 2001), sugere que algum desses insetos possa, no futuro, ser empregado no controle biológico de espécies de Senecio.

O comportamento fenológico, influenciado por vários fatores, permite a presença de espécies de Senecio nos campos, inclusive sua emergência e brotação, em qualquer período do ano, favorecendo a ingestão, quando outros fatores epidemiológicos também ocorrem. Dentre as variáveis epidemiológicas, considera-se o outono-inverno como época mais favorável à ingestão da planta (Barros et al. 1987, Méndez \& Riet-Correa 2000). Porém, se as condições ambientais, como a precipitação, umidade do solo e a cobertura vegetal, são favoráveis à emergência de espécies de Senecio, o seu desenvolvimento pode ocorrer em qualquer época do ano e, consequientemente, a ingestão e a intoxicação. Ao considerar-se o outono e o inverno como períodos propícios à emergência e ao estabelecimento de plântulas (Castellani et al. 1999) e, como nesse estádio a planta é mais facilmente ingerida nas condições ambientais da região estudada (Méndez 1993), é provável que seja, essa época, o período crítico de ingestão pelos animais. No entanto, pelas Fig. 1 e 2, observa-se que sempre há espécies de Senecio em está- 
dio vegetativo, o que indica constante disponibilidade aos animais.

É evidente que para a ocorrência da intoxicação por espécies de Senecio é necessário a confluência de diversos fatores relacionados ao agente (Senecio), ao ambiente e aos animais. As variáveis fenológicas em relação ao agente Senecio, determinadas pelas condições ambientais, especialmente a umidade e a luz para a emergência e brotação, e a temperatura para a floração, contribuem para o estabelecimento e dispersão do mesmo. Outro fator importante relacionado ao ambiente é a disponibilidade de forragem que, sendo inadequada, favorece a ingestão de espécies de Senecio principalmente quando estão em desenvolvimento. A ausência de ovinos ou caprinos, menos suscetíveis que os bovinos (Pearson 1993, Radostits et al. 1999, Tokarnia et al. 2000), o período de permanência dos bovinos em áreas infestadas por Senecio spp., a densidade populacional, e a susceptibilidade individual são alguns dos fatores relacionados aos animais que determinam a ocorrência da seneciose.

\section{REFERÊNCIAS}

Barros C.S., Driemeier D., Pilati C., Barros S.S. \& Castilhos L.M.L. 1992. Senecio spp. poisoning in cattle in Southern Brazil. Vet. Hum. Toxicol. 34(3):241-246.

Beskow W.B. 1995. A study of the factors influencing the emergence and establishment of ragwort (Senecio jacobaea L.) seedlings in pastures. M. Agr. Sc. Thesis, Massey University: New Zealand. 116p.

Borgignon O.J., Piccolo A.L.G. 1981. Fenologia de Hydrocotyle leucocephala Cham. Rodriguésia 33(56):91-99.

Brasil 1973. Levantamento de reconhecimento dos solos do estado do Rio Grande do Sul. Boletim Técnico 30, Divisão de Pesquisa Pedológica, Departamento Nacional de Pesquisa Agropecuária (DNPEA), Ministério da Agricultura. $431 \mathrm{p}$.

Bull L.B. 1955. The histological evidence of liver damage from pyrrolizidine alkaloids: megalocytosis of the liver cells and inclusion globules. Aust. Vet. J. (31):33-40.

Cabrera A.L. \& Klein R.M. 1975. Compostas, 2. Tribo: Senecioneae, p.126222. In: Reitz R. (ed.) Flora Ilustrada Catarinense, Herbário Barbosa Rodrigues, Itajaí, SC.

Castellani T.T., Caus C.A. \& Vieira S. 1999. Fenologia de uma comunidade de duna frontal no sul do Brasil. Acta Bot. Bras. 13(1):99-114.

Caxambú M.G. 1999. Intoxicação por Senecio spp. no sul do Brasil: estudo ecológico, epidemiológico e controle biológico. Relatório, Fundação de Amparo à Pesquisa do Rio Grande do Sul (FAPERGS), Proc. no 98/1845.7, p.2-14.

Cestaro L.A. 1984. Ecologia do estrato herbáceo da mata de araucária da Estação Ecológica de Aracuri, Esmeralda, Rio Grande do Sul. Dissertação (Mestrado em Ecologia), Instituto de Biociências, UFRGS, Porto Alegre. 110p.

Coombs E.M., Bedell T.E. \& McEvoy P.B. 1991. Tansy ragwort (Senecio jacobaea): importance, distribution, and control in Oregon, p.419-428. In: James L.F., Evans J.O., Ralphs M.H. \& Child R.D. (ed.) Noxious Range Weeds. Westview Press, San Francisco.

Coombs E.M., Radtke H., Isaacson D.L. \& Snyder, S.P. 1996. Economic and regional benefits from the biological control of tansy ragwort, Senecio jacobaea, in Oregon, p.489-494. In: Proc. IX Int. Symposium on Biological Control of Weeds, Stellenbosch, University of Cape Town.

Coombs E., Mallory-Smith C., Burrill L.C., Callihan R.H., Parker R. \& Radtke H. 1997. Tansy ragwort. Senecio jacobaea L. P.N.W. 175:1-8.

Costa C.S.B., Seeliger U. \& Cordazzo C.V. 1988. Distribution and phenology of Andropogon arenarius hackel on coastal dunes of Rio Grande do Sul, Brazil. Revta Bras. Biologia 48(3):527-536.
Driemeier D., Barros C.S.L. \& Pilati C. 1991. Seneciose em bovinos. Hora Vet., Porto Alegre, 59:23-30.

Driemeier D. \& Barros C.S.L. 1992. Intoxicação experimental por Senecio oxyphyllus (Compositae) em bovinos. Pesq. Vet. Bras. 12 (1/2):33-42.

Embrapa 1999. Sistema Brasileiro de Classificação de Solos. Centro Nacional de Pesquisa de Solos, Rio de Janeiro. 412p.

Fournier L.A. 1976. El dendrofenograma, una representación gráfica del comportamiento fenológico de los árboles. Turrialba 26 (1):96-97.

Harper J.L. 1958. The ecology of ragwort (Senecio jacobaea) with especial reference to control. Herbage Abstr. 28 (3):151-157.

Harper J.L. \& Wood W.A. 1957. Biological flora of the British Isles: Senecio jacobaea L. J. Ecology 45:617-637.

Karam F.S.C. 2001. Fenologia de quatro espécies tóxicas de Senecio (Asteraceae) e aspectos epidemiológicos da seneciose na região sul do Rio Grande do Sul. Dissertação (Mestrado em Patologia), Faculdade de Veterinária, UFPel, Pelotas. 107p.

Kissmann K.G. \& Groth D. 1992. Plantas Infestantes e Nocivas. Tomo II. BASF Brasileira S.A., Indústrias Químicas, São Paulo. 798p.

Larcher W. 2000. Ecofisiologia Vegetal. Rima artes e textos. São Carlos. 531p.

Liddell J.R., Stermitz F.R. \& Barros C.S. 1992. Pyrrolizidine alkaloids from Senecio oxyphyllus, a Brazilian poisonous plant. Biochemical Systematics and Ecology 20(4):393.

Machado I.C.S., Barros L.M. \& Sampaio E.V.S.B. 1997. Phenology of caatinga species in Serra Talhada, PE, Northeastern Brazil. Biotropica 29 (1):57-68.

Madanes N., Vicari R. \& Bonaventura S.M. 1996. Fenologia de las especies de los bordes de caminos en agroecosistemas y su relación con los parámetros climáticos. Parodiana 9 (1/2):149-158.

Matzenbacher N.I. 1998. O complexo "Senecionoide" (AsteraceaeSenecioneae) no Rio Grande do Sul - Brasil. Tese (Doutorado em Botânica), Instituto de Biociências, UFRGS, Porto Alegre. 274p.

McClements I., Courtney A.D. \& Malone F.E. 1998. Management and edaphic factors related with the incidence of marsh ragwort, p.40-44. In: Garland T. \& Barr A.C. (ed.) Toxic Plants and other Natural Toxicants. Guildford and King's Lynn, Biddles Ltd, Oxon.

McEvoy P., Cox C. \& Coombs E. 1991. Successful biological control of ragwort, Senecio jacobaea, by introduced insects in Oregon. Ecological Applications 1 (4):430-442.

Méndez M.C. 1993. Intoxicação por Senecio spp., p. 43-57. In: Riet-Correa F., Méndez M.C. \& Schild A.L. (ed.) Intoxicações por Plantas e Micotoxicoses em Animais Domésticos. Editorial Agropecuaria Hemisferio Sur, Montevideo.

Méndez M.C. 1997. Intoxicação por Senecio spp. no Rio Grande do Sul. In: Alternativas de controle de Senecio spp. - desenvolvimento de um projeto interdisciplinar e interinstitucional. Seminário, curso de mestrado em veterinária, Universidade Federal de Pelotas, RS.

Méndez M.C. \& Riet-Correa F. 2000. Plantas hepatotóxicas, p.9-29. In: Méndez M.C. \& Riet-Correa F. (ed.) Plantas tóxicas e Micotoxicoses. Editora Universitária, Pelotas.

Méndez M.C., Riet-Correa F., Schild A.L. \& Martz W. 1990. Intoxicação experimental por cinco espécies de Senecio em bovinos e aves. Pesq. Vet. Bras. 10 (3/4):63-69.

Miranda I.S. 1995. Fenologia do estrato arbóreo de uma comunidade de cerrado em Alter-do-Chão, PA. Revta Brasil. Bot. 18 (2):235-240.

Morellato P.C. \& Leitão-Filho H.F. 1996. Reproductive phenology of climbers in a Southeastern Brazilian forest. Biotropica 28 (2):180-191.

Moreno J.A. 1961. Clima do Rio Grande do Sul. Secretaria da Agricultura do Estado do Rio Grande do Sul, Porto Alegre. 42p.

Mueller-Dombois D. \& Ellenberg H. 1974. Aims and Methods of Vegetation Ecology. John Wiley, New York. 547p.

Nimer E. 1990. Clima, p.151-157. In: Geografia do Brasil, Região Sul. 2. IBGE, Rio de Janeiro.

Pearson E.G. 1993. Moléstias do sistema hepatobiliar, p.839-857. In: Smith 
B.P. (ed.) Tratado de Medicina Interna de Grandes Animais. Vol.1. Manole, São Paulo.

Radostits O.M., Gay C.C., Blood D.C. \& Hinchcliff K.W. 1999. Veterinary Medicine. $9^{\text {th }}$ ed. W. B. Saunders, London. 1881 p.

Riet-Correa F. \& Medeiros R.M.T. 2000. Toxic plants for ruminants in Brazil and Uruguay: economic impact, control measures and public health implications. XXI World Buiatrics Congress., Punta del Este, Uruguai. (CD Room)

Thompson K., Grime J.P. \& Mason G. 1977.Seed germination in response to diurnal fluctuations of temperature. Nature 267:147-149.
Tokarnia C.H., Döbereiner J. \& Peixoto P.V. 2000. Plantas hepatotóxicas, p.80110. In: Tokarnia C.H., Döbereiner J. \& Peixoto P.V. (ed.) Plantas Tóxicas do Brasil. Helianthus, Rio de Janeiro.

Van der Meijden E. \& van der Waals-Kooi R.E. 1979. The population ecology of Senecio jacobaea in a sand dune system. J. Ecology 67:131-153.

Vitorino M.D. 1997. Controle biológico de plantas indesejáveis. In: Alternativas de controle de Senecio spp - desenvolvimento de um projeto interdisciplinar e interinstitucional. Seminário, curso de mestrado em veterinária. Universidade Federal de Pelotas, RS.

Walter H. 1977. Zonas de vegetación y clima. Omega, Barcelona. 245p. 